\title{
Experiential Learning in Collegiate Aviation: The Use and Assessment of Internships
}

\author{
C. Daniel Prather \\ Middle Tennessee State University
}

\begin{abstract}
Experiential learning, in general, and internships, in particular, are increasing in popularity as students endeavor to gain real-world experience in their chosen career field prior to college graduation. As noted by Steffes (2004), "Providing students with a connected view of learning that integrates their real world experiences with classroom lectures and discussion can create a powerful learning environment” (p. 49). It is this powerful learning environment that was the focus of this paper. As part of this study, a comprehensive literature review and survey of UAA institutional members was conducted. This resulted in a more thorough understanding of the history of experiential learning, the various types of experiential learning, various aspects of internships, the role of internships in collegiate aviation, and current methods of assessing internships both within collegiate aviation and other academic fields. The paper concluded by presenting various recommendations in how to best assess internships to ensure the growth and continued success of this form of experiential learning in higher education.
\end{abstract}

\section{INTRODUCTION}

Students transitioning into the workplace upon graduation are often surprised at the magnitude of the transition, as a result of the new roles and expectations present in the workplace. While in college, students get regular feedback about their performance through faculty comments and academic grades. Students are transient and must learn new concepts quickly. They normally participate in highly structured programs that provide a great amount of direction. Schedules are flexible and allow for frequent breaks and time off during holiday periods and between semesters. Opportunities to create and explore knowledge are mostly through individual efforts.

On the other hand, the workplace can be quite different. Feedback is infrequent and less precise. Employees are considered permanent, unless something changes. Due to this permanent nature, employees generally have a longer time period to learn their specific tasks. Employees normally work in highly unstructured work environments and engage in tasks with little direction. Employees have limited time off and work within structured schedules. They work under supervision, and oftentimes in teams, to get results for the organization (Bialac \& Wallington, 1985; Jones, 2002).
Regardless of these differences between the college and work environments, students can engage in learning experiences that more effectively prepare them for this transition to professional life. These learning experiences are referred to as experiential learning. Experiential learning has been defined as:

That learning process that takes place beyond the traditional classroom and that enhances the personal and intellectual growth of the student. Such education can occur in a wide variety of settings, but it usually takes on a 'learn by doing' aspect that engages the student directly in the subject, work, or service involved. (Katula \& Threnhauser, 1999, p. 238)

\section{METHODOLOGY}

This study of experiential learning was conducted as a case study inquiry with qualitative attributes. As Yin (2003) explains, the case study is preferred when "a 'how' or 'why' question is being asked about a contemporary set of events, over which the investigator has little or no control” (p. 9). Indeed, when exploring how internships are currently being assessed, and why some methods of assessment are more appropriate or preferred, 
the case study stood out as the most appropriate research design for this research effort.

The study involved a review of the literature on experiential learning, not only in collegiate aviation, but in other academic fields as well. Following guidance from Yin (2003), multiple sources of evidence were used. Specifically, sources include relevant literature on experiential learning (both aviation specific and non-aviation specific), as well as the American Association of Airport Executives (AAAE) Academic Relations Committee Web site and the Airport Management Internship Program Guide produced by AAAE (AAAE, n.d.). The qualitative component allowed for a greater understanding of the history of experiential learning in higher education, some types of experiential learning in use today, the role of experiential learning in higher education, various aspects of internships, and the role of internships in collegiate aviation.

Additionally, this study included a survey of University Aviation Association (UAA) institutional members to determine the role of internships in collegiate aviation, as well as the current methods of assessing of aviation internships. An original, researcher-designed questionnaire was developed after completion of the comprehensive literature review, so that the various methods of internship assessment utilized in other academic fields could be included in the questionnaire. To minimize expense and the time necessary to develop and distribute the survey, the Survey Monkey Web site was utilized to create a brief, on-line questionnaire with eight items (See Appendix A). Prior to distribution, the questionnaire was reviewed by three individuals in the field of collegiate aviation, which allowed for further refinement of the questionnaire. Utilizing the UAA list of institutional members, an email with a link to the on-line, researcher-designed questionnaire was sent to all 104 institutional members of the UAA in October $2006(\mathrm{~N}=104)$. The initial response rate was 34 percent $(n=35)$. After a follow-up email to non-respondents, the response rate increased to 50 percent $(n=52)$. The survey results provide a better understanding of the role of internships in collegiate aviation, and current methods of assessing of internships within this field.

\section{Brief History of Experiential Learning}

The onsite training of new workers or young craftsmen is not a novel idea. Indeed, the craft professions, through apprenticeship and journeyman certification, have utilized the learn by doing method for centuries in an effort to pass down expertise from one generation to another (Steffes, 2004). Additionally, the medical profession, for example, has a long history of supporting interns who are there to assist, learn from, and work with more experienced physicians (Moriber, 1999). Labs are another manner in which students have supplemented classroom learning over the years.

The formal use of work experience in higher education began in 1906 at the University of Cincinnati. In that year, Herman Schneider instituted a cooperative education program that was designed to extend the traditional college laboratory (Ruiz, 2004a). In that sense, allowing students to gain work experience within their chosen profession, while still enrolled at the institution, created a tremendous opportunity to unite classroom theory with real-world experience. It appears that the benefits of experiential learning were clearly evident, as the number of institutions offering such an innovative learning experience began growing.

Today, whether in the form of internships, service learning, or co-ops, experiential learning is offered at approximately 900 community colleges, senior colleges, and graduate schools in the United States (Ruiz, 2004a). Clearly, many students look forward to their experiential learning opportunity, with some even choosing a college based on the potential for internship opportunities.

\section{Types of Experiential Learning}

Various types of experiential learning are in use today. Service learning is one form of experiential learning that is gaining in popularity. As proposed by Steffes (2004), "Service learning is a long way from the center of the academic center stage in higher education, but it is moving in that direction with increasing speed” (p. 48). Service learning experiences include opportunities for students to apply knowledge and skills acquired in the classroom, while also developing new skills, through active participation in community-based projects. 
Specifically, the service learning experience is preplanned and encourages students to analyze and reflect on what they have learned during the experience. The service learning concept is based on the "pedagogical principle that learning and development do not necessarily occur as a result of experience itself, but as a result of a reflective component explicitly designed to foster learning and development” (Clark, 1999, p. 654-55). This need for reflection has been highlighted as a necessary ingredient in experiential education (Clark, 1999). This reflection differentiates service learning from volunteer work, wherein students invest time without connecting their service to their own reactions or educational objectives (Schwartzman, 2002). Service learning students not only provide direct community service, but also learn about the context in which the service is provided and understand the connection between the service and their academic coursework (Clark, 1999). In essence, service learning emphasizes reciprocity by creating a learning opportunity for students, while also serving the needs of the community (Kretchmar, 2001). Service learning students always serve at non-profit agencies, never get paid for their work, and engage in activities that benefit the agency, while allowing the student to tie their work in with the academic content of the class in which the service learning option was offered (Prentice \& Garcia, 2000). Although it may appear that service learning is similar to other types of experiential learning, service learning differs in that "the provider and the recipient benefit equally from emphasis on both the service being provided and the learning that is occurring” (Haessig \& La Potin, 1999, p. 14). Typical service learning placements may include day care centers, homeless shelters, nursing homes, hospitals, Head Start programs, English as a Second Language programs, hospices, schools, and programs for people with disabilities (Cairn \& Cairn, 1999; Prentice \& Garcia, 2000).

One of the more popular forms of experiential learning, at least among aviation students, is the internship. As noted in Ruiz (2004a), "the word is out that internships offer high school and college students a foolproof way to get a head start in the search for employment and career success” (p. 89). Often considered a capstone learning experience, internships take the form of a structured and supervised professional experience in an approved organization or agency where students earn academic credit upon completion of the experience (Jones, 2002). Referring to any temporary work experience in either a for-profit or nonprofit setting, the internship allows the intern the opportunity to learn while working (Ruiz, 2004a). The flexibility in the internship arrangement may allow the student to intern while continuing to maintain a normal course load at school or during a summer or semester break from school. Indeed, many internships take place during an academic semester (or longer) and require the intern to work full-time while enjoying a break in their studies. Typical internship placements for aviation students may include airports, airlines, fixed base operators, and governmental aviation agencies. According to UAA institutional members surveyed, in fact, these four segments of the aviation industry were the most popular in which to place interns, with aviation associations (such as the Aircraft Owners and Pilots Association [AOPA] and the National Business Aviation Association [NBAA]) and corporate aviation also being popular.

Similar to an internship, cooperative education (co-op) was derived from a cooperative relationship between the institution and employer. As with internships, the co-op may be a degree requirement or an elective. Students normally work full-time in the majority of co-op programs, while taking a break from their studies. Traditionally, only departments of engineering, business, and science participated in cooperative education (Ruiz, 2004a). However, the co-op arrangement is today becoming a popular form of experiential learning in many other academic departments as well. Typical placements for co-op students are similar to internship placements.

\section{Unique Aspects of Internships}

As with other forms of service learning, internships have unique characteristics. According to Jones (2002), the skills most frequently developed through internships are (a) critical thinking, (b) dealing with the pressures 
of professional work, (c) applying classroom learning, (d) working on challenging duties and assignments, (e) gaining a perceived edge in the job market, (f) learning about real-world politics in the workplace, (g) enhanced communication skills, (h) clarifying career direction, and (i) learning to work in teams. In contrast, the skills most frequently developed through service learning are (a) increased sense of citizenship, (b) development of stronger analytical and problem-solving skills, (c) enhanced personal development, (d) increased leadership skills, (e) greater cultural awareness and tolerance, (f) enhanced social development skills, and (g) improved interpersonal development (Steffes, 2004).

In addition to the skills developed during an internship experience, a number of researchers (AAAE, n.d.; Bialac \& Wallington,1988; Dixon, Cunningham, Sagas, Turner, \& Kent, 2005; Theisse, NewMyer, \& Widick, 1992) have discussed the various benefits of internships. Benefits to students include (a) gaining practical experience and exposure to the dynamics of a real organization; (b) the opportunity to make many valuable contacts in the aviation industry; (c) challenging jobs that improve the student's work skills and assist in further defining the skill set; (d) a sense of importance and belonging that results from attachment to an organization; (e) helping students determine if they are pursuing a career path appropriate to their actual skills and interests; (f) the opportunity to explore different professional settings; (g) the ability to earn academic credit; (h) receiving detailed orientation to a new and unfamiliar work site, and (i) possible permanent employment for the intern.

Benefits accrue to the firm providing the internship opportunity as well. These benefits include (a) obtaining temporary, talented help that serve as a potential future hiring pool; (b) the actual work the interns perform; (c) a low cost labor source; (d) the potential to preview potential future employees; (e) seeing how an intern performs; and (f) receiving the intern's knowledge of the latest academic information and skills (Bialac \& Wallington, 1988; Cook, Parker, \& Pettijohn, 2004; Theisse et al., 1992).

Similarly, the institutions arranging for and offering internship opportunities for students also realize benefits. Benefits noted by researchers such as Bialac \& Wallington,1988; Cook et al., 2004; and Theisse et al., 1992, include (a) receiving verification of the appropriateness of their teachings, as well as developing new channels for placement of future graduates; (b) the infusion of new ideas and industry information from current and returning interns; (c) institutional recognition and credibility; (d) a healthy recruiting mechanism; and (e) gaining credibility and relationships with industry.

Interestingly, in an evaluation of how beneficial an airport internship program is to both the intern and the airport, Prather (1999) discovered in a study of 200 airport managers that 92 percent of respondents feel an internship is either "beneficial" or "extremely beneficial" to the Intern. However, only 59 percent of respondents feel the internship is either "beneficial" or "extremely beneficial" to the Airport.

Although benefits are plentiful, potential problems exist as well. Theisse et al. (1992) explain that, for students, there is the potential that they will be assigned routine tasks that do not enhance the student learning. Students also face problems such as inappropriate pay levels, uncooperative colleagues or supervisors, labor union difficulties, and travel costs from the educational institution to the internship site. Educational institutions face the challenge in establishing "appropriate, legally correct, and internship-specific selection processes” (p. 262). As part of this challenge, there should be equal opportunity for internships in which all eligible aviation students are encouraged to apply. Internship providers must take time to establish internship experiences that match the needs of both the provider and the students. Pay and benefits must also be considered. Liability issues may also have to be satisfied before a proposed internship program is approved. Lastly, the aviation industry must oversee internships for "fairness, quality, pay standards, credit standards, and overall quality of work standards" (Theisse et al., 1992, p. 262). Further, the industry should support the use of interns and promote the establishment of internship programs by a large number of industry members. 
Further recognizing the potential for problems, Cook et al. (2004) explain that if an intern program is not carefully thought out, it may result in a disappointing experience for the intern. Disappointments may result from unclear standards, misunderstanding by students regarding the merits of the job, and the misrepresentation by the firm regarding the duties required.

Granted, learning, in the form of an internship experience, can be fraught with unexpected problems, unanticipated issues, and unresolved conflicts that may appear to greatly interfere with learning. However, as Clark (1999) pointed out, these experiences actually becoming part of the learning itself.

\section{Considerations in Establishment of an Internship Program}

Prior to establishing an internship program, consideration should be given to whether the internship experience is a requirement for students. Although this presents the problem of arranging an adequate supply of internships for the students, Cook et al. (2004) stated that "if the university's mission is to graduate well-rounded individuals, the internship experience possibly should be an academic requirement rather than an option" (p. 185).

However, Ferguson (1998) believes that "not every student should qualify for an internship, nor should every company be used as an internship site” (p. 23). Additionally, Posey et al. (1988) stated that an internship requirement could potentially place an undue financial strain on some students and prohibit them from completing their degree. However, Flouris and Gibson (2002) feel that additional internship experiences should be added to the curriculum so that "students will have a more realistic view of upcoming career and workload responsibilities [among other issues]”. (p. 38)

Whether considered mandatory or optional, those organizations taking the admirable first step in establishing an internship program, as well as aviation programs considering offering internships, should consider a number of issues unique to this form of experiential learning in an effort to avoid having a poor intern experience and minimize any chance of unrealized expectations. For instance, Posey, Carlisle, \&
Smellie (1988) remind firms that (a) directing an intern takes time and energy, (b) interns usually lack actual hands-on experience, and (c) an organization must set reasonable expectations for what an intern can produce in a short time. Additionally, high-quality internships generally (a) encourage contact between faculty and students, (b) develop cooperation among students, (c) expose students to numerous active learning techniques, (d) provide for prompt, ongoing feedback regarding performance, (e) allow students to spend allocated times on multiple tasks as they strive to achieve high expectations, and (f) help students learn to respect diverse talents and ways of learning (Jones, 2002).

As a result of a study conducted by Dixon et al. (2005), various recommendations were presented in an effort to enhance the internship and the affective organizational commitment of interns. First, employers should provide challenging jobs, as opposed to routine tasks. Challenging jobs communicate to interns that they are capable and valuable; thus, the interns will be more willing to commit to the organization. Challenging jobs will prevent intern comments such as, " $75 \%$ of my internship involved working in the mail room. I don't feel that I learned a thing stuffing mailboxes" (Ruiz, 2004b, p. 53). Next, organizations may want to review the manner in which supervisor-intern relationships are structured. A clear chain of command and regular interaction with the supervisor leads to greater affective organizational commitment. Lastly, educators need to work closely with the sponsoring organizations to ensure that jobs are both challenging and well supervised.

In an effort to assist academic programs that include an internship component, Diambra, Cole-Zakrzewski, and Booher (2004) presented several recommendations based on research conducted. First, since students find internships highly enjoyable and valuable, a significant amount of academic program resources should accompany this learning experience. Second, internship coordinators and instructors must ensure that sufficient planning, as well as structure, supervision, monitoring, and opportunities for ongoing reflection, are 
provided to students during the internship experience.

Lastly, the internship program should be evaluated annually, if possible. Reviewing a program's purpose and objectives will, according to Ferguson (1998), allow ways in which to improve a program and enable the internship to better meet its goals. Important in this evaluation is seeking input from students and site supervisors.

\section{Role of Internships in Collegiate Aviation}

Internships are currently a widely utilized form of experiential learning for students in collegiate aviation. In fact, of the UAA institutions surveyed, 79.6 percent $(n=39)$ report they offer internships for their aviation students. These many internship opportunities give students the invaluable experience of working for a particular airline, airport, fixed base operator, or aviation consulting firm, for instance, while earning academic credit and supplementing their formal education. Of the UAA institutions surveyed, 89.7 percent $(n=35)$ award academic credit for successfully completing an aviation internship. For a typical internship, those programs on a semester hour basis award three credit hours $(n=17)$ or six credit hours $(n=8)$. Programs on quarter hours, usually award two quarter hours per internship. Prather (1999) noted that, "Individuals no longer may be able to enter the field [of airport management] with sufficient education alone. Experience is now a necessity and for those recently graduated, this experience may seem impossible to obtain” (p. 54). If it were not, that is, for internships.

Thiesse et al. (1992) summarize the purpose and benefits of an aviation internship program:

One way in which a continuous stream of qualified, enthusiastic, and wellmotivated employee candidates can be attracted to an FBO or airport is through an internship arrangement with a university or community college that has an aviation degree program. Internships are an important part of most of these degree programs because they 'build a bridge' between the degree-oriented academic world and the employment-oriented real world. Such programs are also recognition of the fact that college courses and licensing are only one part of the task of education. On-the-job training in the industry itself adds the finishing touch to university/community college aviation degree graduates that makes them more employable. (p. 254)

Many agree that internships provide the critical transition for students as they depart academia and enter into industry. In addition, internships establish the necessary base for employment upon graduation. In a survey of former interns, Gibala and Stuhldreher (2001) discovered that 100 percent recommended mandatory internships as part of the academic experience. Additionally, according to Flouris and Gibson (2002), "many students do not have a reasonable understanding of the workload levels they face in aviation management positions" (p. 35). Thus, the internship experience would provide insight into this area.

Although internships are a popular component in the education experience for many aviation students, some are quick to criticize internships. According to Ferguson (1998), critics claim that faculty often create activities that are unrelated to the fieldwork experience. Additionally, the critics claim that such activities do not accurately evaluate student performance, especially when most students receive an "A". With 55.3 percent $(n=21)$ of responding UAA institutional members granting a letter grade for the internship experience, this is valid concern. As Ruiz (2004a) states, "In order for experiential education to pass the traditional academic muster of the faculty, substantiation of its intellectual benefit is a must” (p. 90). How do those in higher education assess the benefits of internships to ensure that various enhancements to student learning have occurred?

\section{Assessment of Internships}

Historically, assessment of student learning was conducted by the professor. The professor required certain tasks to be successfully completed and then measured the performance on these tasks against certain educational outcomes. Academic grades were then assigned 
to enable students to determine how well they met the objectives. In experiential learning, however, there appear to be additional ways to measure student learning. First, however, a unique and appropriate assessment strategy should be designed.

In designing an appropriate assessment strategy, the following questions from Holland (2001, p. 54) should be answered: “(a) What is the purpose of my assessment, (b) Who wants or needs the assessment information, (c) What resources are available to support assessment, (d) Who will conduct the assessment, and (e) How can I ensure the results are used?" In answering these questions, Holland (2001) reminds the reader that "a comprehensive assessment design, introduced at the earliest stages of a collaborative endeavor . . . not only measures the impacts of the learning activity, but helps to enrich and sustain the underlying partnership itself" (p. 53). Effective assessment strategies generate the evidence necessary to sustain internal and external support for experiential learning programs. Assessment can also "identify problem areas where improvement is needed, illuminate key issues and challenges, compare and contrast strategies and actions, and document successes that warrant celebration" (Holland, 2001, p. 53).

Ferguson (1998) proposes four key factors that must be considered when developing evaluation criteria. First, the internship coordinator and the on-site supervisor must develop meaningful assignments and projects that require the student to demonstrate written and verbal communication skills, as well as professional knowledge gained on the job. These items could then be placed in a professional portfolio. Second, a balance must be maintained between keeping the student busy and not overburdening the student. Third, the on-site supervisor could be involved in the intern's evaluation by, for instance, completing a questionnaire that assesses specific criteria such as timeliness, cooperation, and work, in addition to normal performance evaluations. Lastly, as part of grading, faculty with expertise in specific areas should be responsible for evaluating assignments in those specific areas. To reduce grade inflation, faculty should strive to develop quality written assignments. Conversely, implementing a pass-fail system may be appropriate. Cook et al. (2004) suggest that interns should receive a pass/fail grade for their academic credit, rather than a letter grade. Interestingly, the students these researchers surveyed also agreed with this premise.

Since one of the primary goals of the internship is to enable students to become more self-directed in their own learning, the use of self-assessment is beneficial. Some intern programs allow the students to assess themselves "by analyzing their ability to use an array of group skills, work with others to solve real problems, perceive and respond appropriately to different cultures, operate from a personal working definition of leadership, and form an understanding of the needs of a pluralistic democracy" (Jones, 2002, p. 68).

Alm (1996) admitted that academic quality can be a significant issue with internships. As a result, she proposes the use of student journals to improve the academic quality of internships. The goal of journal writing, she explains, is to help students connect classroom knowledge with knowledge gained through the internship. Keep in mind, however, that journal writing, although beneficial, may seem daunting to students who are required to create new meaning and understanding for themselves. Students can get started by asking themselves open-ended questions about their internship experience or reflecting on significant events or challenges encountered. Faculty also have a role to play during the internship by reviewing and commenting on journals, providing encouragement and focus, and helping the student to integrate the internship with previous classroom experience. Lastly, grading criteria should relate to the purpose of the journal writing assignment, that is, to help students reflect on their internship experiences.

An additional assessment tool, more commonly utilized in medical residency training, is peer assessment. In a study conducted by Thomas, Gebo, and Hellmann (1999), it was discovered that peer review is both reliable and feasible, provides somewhat different information (especially in areas of humanistic and professional behaviors) than faculty assessments, and is acceptable to residents. Granted, the use of peer assessment is 
not without difficulties, especially if only one intern is working at a particular location.

In an effort to create performance-based assessment specifically for service learning projects in Minnesota secondary schools, Cairn and Cairn (1999) utilized journal writing, selfassessment, research papers, observation during site visits by an instructor, and evaluation of performance by agency supervisors. They are quick to point out that journals are the most common form of assessment for service learning, in particular. "Depending on course objectives," explained Cairn and Cairn (1999, p. 67), "instructors may weigh the relevance of journal entries, the quality of writing, the accuracy of observations, the depth of understanding of the host agency, and the student's ability to reflect on and improve his or her performance."

In discussing the assessment of community health internships, Gibala and Stuhldreher (2001) focus on a journal and major project. The journal is a weekly log that details the student's work. The internship site supervisor also contributes to this journal by evaluating the intern's performance in (a) the ability to develop effective working relationships with staff, (b) acceptance of supervision and constructive criticism, (c) effective communication with clients and peers, and (d) capacity to relate learning to new experiences. The major project is intended to demonstrate mastery of skills and abilities of an entry-level community health professional.

At the Business Department of Queensborough Community College in New York, the internship experience is recognized by a three credit-hour course. This course has several requirements which must be met by interns. The intern supervisor is responsible for ensuring the student works a minimum number of hours and evaluating the intern's work performance. Additionally, daily log sheets are required to be turned in on a weekly basis. These logs record the various tasks performed and problems encountered on the job. Further, three seminar workshops are held during the semester and attendance of interns is mandatory. In the seminar, students are expected to complete writing assignments each week that includes journals and observation notes. These observations then provide for rich discussion and analysis as students interact and share about various intern experiences. Interns are also required to complete a final project. Lastly, students having successfully completed an internship submit a final report detailing the internship experience (Jones, 2002; Moriber, 1999).

In the American Association of Airport Executives (AAAE) Airport Management Internship Program Guide, assessment methods include testing, supervisor evaluation, journal writing, and a required final project. First, the guide recommends take-home tests to be administered by each of the departments in which the intern is assigned. Incorrectly answered questions on these written tests must then be resubmitted correctly prior to moving to the next department. Second, the guide recommends evaluation by supervisors. These evaluations conducted both verbally and in writing, should be conducted by the appropriate departmental supervisor on a quarterly basis. Third, journal writing is recommended as a means to enhance the intern's experience, and provide a means for supervisors to gauge the intern's thoughts on the experience thus far. Lastly, the objective of the final project should be to promote accountability, self-discipline, and forward thinking on the part of the intern. All of the intern's experiences may assist in the creation of this final project, which should then be presented to staff (AAAE, n.d.). These and other areas are evaluated utilizing the Internship Evaluation Sheet and the associated performance elements (Appendix B).

One manner of assessment that is widely utilized is the portfolio method. This method was successfully utilized by the Education faculty at the University of Wisconsin-Oshkosh to evaluate student learning via internships. First, faculty collaborated with students to determine the specific outcomes that were important. Faculty also discussed with students what types of evidence would be collected to demonstrate student growth toward these outcomes. Students then worked with faculty to generate criteria for judging the evidence. In this instance, the criteria included assessments of (a) quantity of portfolio items, (b) level of creativity, (c) level of reflection, 
(d) appropriateness of evidence, (e) usefulness of ideas to future teaching and learning contexts, (f) self-initiation section, (g) quality of change, (h) variety of activities and evidence, (i) organization, and (j) time and effort invested (Jones, 2002). During the internship, students decided which evidence to include in their portfolios and were also asked to reflect on samples of their work. In this instance, students typically discussed how their perceptions had changed as a result of the internship, what was being learned on the job, and what particular challenges they were facing. The actual assessment and grading of the internship experiences was accomplished via three different and distinct strategies. The first method involved a self-evaluation by students of their portfolios according to negotiated criteria. The professor (or internship coordinator) then reviewed the self-evaluation and negotiated with students prior to reaching a final grade. A second method involved the instructor retaining full control over the grading process and assigning a grade based on previously established criteria. Thirdly, two other professors were involved in assigning ratings to the portfolios, which were then reviewed by the main professor, who met with the student and determined a final grade for the portfolio. (Jones, 2002).

\section{Current Aviation Internship Assessment Practices}

Of the 52 institutions responding to the survey conducted as part of this study, 41 reported that they offer internships to their aviation students. Of these 41 programs, it is clear the vast majority place responsibility for assessing the intern on both the employer (intern provider) and faculty (intern coordinator). Interestingly, five programs also allow for some type of self-assessment by the student.

What forms of assessment are currently in use by these programs? The top three include (a) completion of internship, (b) intern on-thejob performance, and (c) intern final report. Other forms of assessment utilized by these programs include (a) journal writing, (b) weekly reports, (c) major project, (d) critical incident logs, (e) portfolio, (f) assessment of learning objectives, (g) mid-term report, and (h) oral presentation to students and faculty (see Figure 1). Regardless of which assessment tools are used, it would seem that the available assessment tools are as unique as the internship programs they are designed to assess. Interestingly, the assessment of internships and the problems therein, is not a new challenge for higher education. As a matter of fact, an article written almost 30 years ago states that "if internships are to receive academic recognition there must be more involved than just a work experience” (Creek \& Thompson, 1977, p. 178).

\section{RECOMMENDATIONS}

Indeed, for institutions offering academic credit for internships, the assessment of the quality of learning that takes place at a worksite is a significant issue for higher education. While some of the strategies presented above may or may not be appropriate in certain situations, it appears that the student benefits from a multimethod approach to assessment. First, the plan for assessment should provide substantial initiative for the intern to self-assess rather than requiring the intern to assume a passive role in being assessed. Whether this includes journals, weekly reports, or critical incident logs, students should be encouraged to reflect on key issues experienced during the internship and reflectively evaluate their internship experience. Second, requiring the intern to complete a final report summarizing the overall internship experience, as well as a critique of their own performance, allows the intern to reflect on those learning outcomes they have achieved and the manner in which those outcomes were reached. Third, the use of portfolios provides a wonderful opportunity to assess the intern's development and progress on a regular basis. Further, a well-developed portfolio may serve as a useful reference once the former intern begins a job search. In the portfolio, the internship coordinator may find reports or proposals prepared by the student, as well as supervisor evaluations. Fourth, the intern's on-site supervisor should prepare evaluations of the intern's performance, including thoughts on the intern's strengths and weaknesses and areas of possible improvement. 


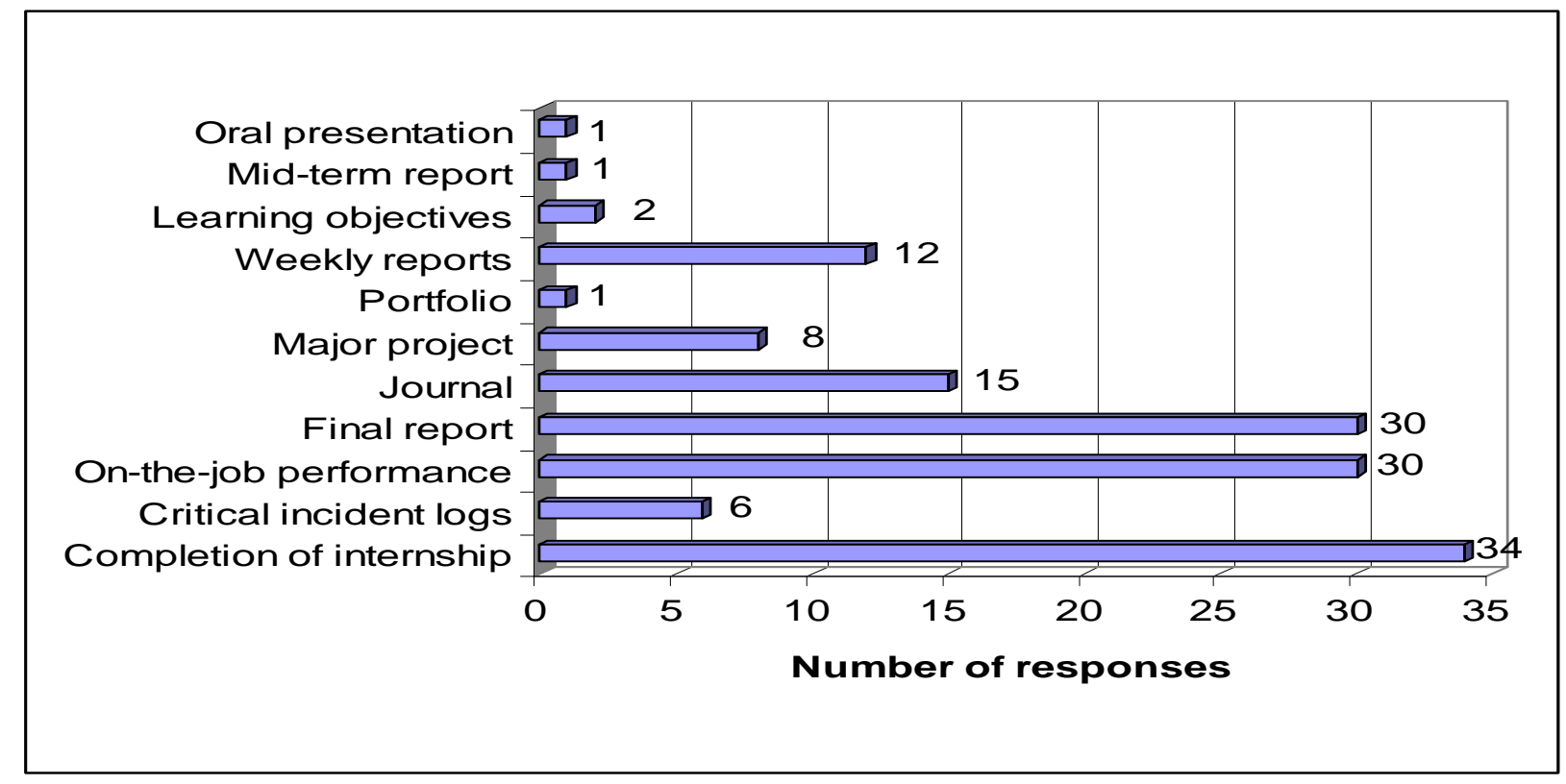

Figure 1. Aviation Internship Assessment Methods

Note: Respondents could select more than one assessment practice; thus, total numbers do not reflect number of respondents.

If the geographical location of the internship allows, group conferences or seminars can be held on campus to allow students engaged in internships to share their experiences, learn about issues in other organizational contexts, and solve problems together. This forum provides a convenient opportunity to gauge how much learning is occurring for the students. Lastly, an academic internship coordinator should be assigned at the home institution to monitor the progress of interns, collect materials from both the supervisors and the interns, evaluate the intern's performance, and assign either a letter grade or a pass-fail rating for the student (depending on institutional grading policy). In essence, by assessing the performance and level of experiential learning displayed by interns longitudinally, contextually, and collaboratively, the grade assigned to each intern should be both reasonable and fair.

\section{CONCLUSION}

In whatever form, experiential learning is becoming a prominent pedagogy of the $21^{\text {st }}$ century. Students are eager to expand the walls of the traditional classroom and have been doing so via distance learning technologies and experiential education. Although the assessment of experiential learning is a concern for higher education, this should not discourage more aviation academic programs from arranging internships, nor should it discount the amount of learning that takes place during an internship. In fact, as more institutions recognize the importance of a real-world work experience for their students, and faculty, and industry get on board in support of such efforts, the graduates of tomorrow will be ensured success as they transition from the role of a student to that of a well-prepared, and even experienced, member of the workforce. 


\section{REFERENCES}

Alm, C. T. (1996). Using student journals to improve the academic quality of internships. Journal of Education for Business, 72(2), 113-115.

American Association of Airport Executives, (n.d.). Airport Management Internship Program Guide.

Retrieved October 23, 2005, from `http://www.aaae.org/members/100_About_AAAE/ 325_AAAE_Committees/150_Academic_Relations/250_Airport_Internship_Info/.

Bialac, D., \& Wallington, C. (1985). From backpack to briefcase. Training and Development Journal, 39(5), 66-68.

Cairn, R., \& Cairn, S. (1999). Service learning makes the grade. Educational Leadership, 56(6), 66-68.

Clark, P. G. (1999). Service-learning education in community-academic partnerships: Implications for interdisciplinary geriatric training in the health professions. Education Gerontology, 25, 641-660.

Cook, S. J., Parker, R. S., \& Pettijohn, C. E. (2004). The perceptions of interns: A longitudinal case study. Journal of Education for Business, 79(3), 179-185.

Creek, L. V., \& Thompson, G. (1977). Management of undergraduate psychology internships. Teaching of Psychology, 4(4), 177-180.

Diambra, J. F., Cole-Zakrzewski, K. G., \& Booher, J. (2004). A comparison of internship stage models: Evidence from intern experiences. Journal of Experiential Education, 27(2), 191-212.

Dixon, M. A., Cunningham, G. B., Sagas, M., Turner, B. A., \& Kent, A. (2005). Challenge is key: An investigation of affective organizational commitment in undergraduate interns. Journal of Education in Business, 80(3), 172-180.

Ferguson, L. H. (1998). Guidelines for a safety internship program in industry. Professional Safety, 43(4), 2226.

Flouris, T. G., \& Gibson, B. (2002). Aviation management job placement: The 2002 perspective. Collegiate Aviation Review, 20(1), 29-48.

Gibala, D., \& Stuhldreher, W. (2001). The internship as a capstone experience: The bridge from academia to practice. Quarterly Bulletin of the Council on Linkages between Academia and Public Health Practice. Public Health Foundation.

Haessig, C. J., \& La Potin, A. S. (1999). Using a program advisory committee and a carousel approach to identify outcomes for service learning. Assessment Update, 11(3), 14.

Holland, B. A. (2001). A comprehensive model for assessing service-learning and community-university partnerships. New Directions for Higher Education, 114, 51-60.

Jones, E. A. (2002). Implementing and assessing internships. In A. Kezar (Ed.), Transforming the curriculum: Preparing students for a changing world (pp. 65-75). San Francisco, CA: Jossey-Bass. (ASHE-ERIC No. ED470041).

Katula, R. A., \& Threnhauser, E. (1999, July). Experiential education in the undergraduate curriculum. Communication Education, 48, 238-248.

Kretchmar, M. D. (2001). Service learning in a general psychology class: Description, preliminary evaluation, and recommendations. Teaching of Psychology, 28(1), 5-10.

Moriber, A. C. (1999). Cooperative internships that work. Community Review, 17: 76-79.

Posey, L. O., Carlisle, K. E., \& Smellie, D. C. (1988). An internship case study. Training and Development Journal, 42(2), 59-64. 
Prather, C. D. (1999). Airport internships: Effectively structuring a departmental rotation internship. Collegiate Aviation Review, 17(1), 53-73.

Prentice, M., \& Garcia, R. M. (2000). Service learning: The next generation in education. Community College Journal of Research and Practice, 24(1), 19-26.

Ruiz, J. R. (2004a). Airline flight operations internships: Perspectives. Journal of Air Transportation, 9(1), 8699.

Ruiz, J. R. (2004b). The most valuable aspects of an airline flight operations internship: The perceptions of former interns. Journal of Aviation/Aerospace Education and Research, 13(3), 43-53.

Schwartzman, R. (2002). Along the path to service-learning. Journal of Public Affairs, 6(1), 43-60.

Steffes, J. S. (2004). Creating powerful learning environments beyond the classroom. Change, 36(3), 46-50.

Thiesse, J. L. NewMyer, D. A., \& Widick, L. L. (1992). FBO and airport internships for university aviation students: Benefits for students, universities, and the aviation industry. Journal of Studies in Technical Careers, XIV(4), 253-264.

Thomas, P. A., Gebo, K. A., \& Hellmann, D. B. (1999). A pilot study of peer review in residency training. Journal of General Internal Medicine, 14(9), 551-554.

Yin, R. K. (2003). Case study research: Design and methods ( $3^{\text {rd }}$ ed.). Thousand Oaks, CA: Sage Publications. 


\title{
APPENDIX A
}

\author{
Internship Assessment Survey
}

\section{Consent}

All UAA institutional members were invited to participate in this study on the use and assessment of internships in collegiate aviation. There are no known risks if you choose to participate, nor will you be penalized if you decide not to participate. There are no rewards (monetary or otherwise) available to those who choose to participate. By completing this on-line survey, you are voluntarily agreeing to participate. Your responses will remain confidential; neither you nor the institution you represent will be identified in the study results. The questionnaire should take no more than 5 minutes to complete.

IRB \#07-060

If you have any questions concerning your rights as a research subject, please contact:

Ms. Tara Prairie

Compliance Officer

Middle Tennessee State University

BAS S245

Murfreesboro, TN 37132

615-494-8918

compliance@mtsu.edu

If you have any questions about this study, please contact:

C. Daniel Prather, A.A.E.

Associate Professor of Aerospace

Middle Tennessee State University

Box 67

Murfreesboro, TN 37132

615-898-2289

dprather@mtsu.edu

Thank you for your time! 
1. Does your aviation program offer (arrange/coordinate) internships for the aviation students at your institution? Survey Monkey allowed use of logic, which directed those answering 'Yes' to this question to skip to question three, while those answering 'No' were directed to question 2 only.

$$
\begin{array}{ll}
\square \quad \text { Yes } \\
\square \quad \text { No }
\end{array}
$$

2. Based on your experience and expertise, which of the following methods do you feel are most appropriate for assessing interns? (Check all that apply)

$\begin{array}{ll}\square & \text { Completion of internship } \\ \square & \text { Critical incident logs } \\ \square & \text { Intern on-the-job performance } \\ \square & \text { Intern final report } \\ \square & \text { Journal writing } \\ \square & \text { Major project } \\ \square & \text { Portfolio method } \\ \square & \text { Weekly reports } \\ \square & \text { Other (please specify) }\end{array}$

3. In which of the following segments of the aviation industry do you typically place interns?

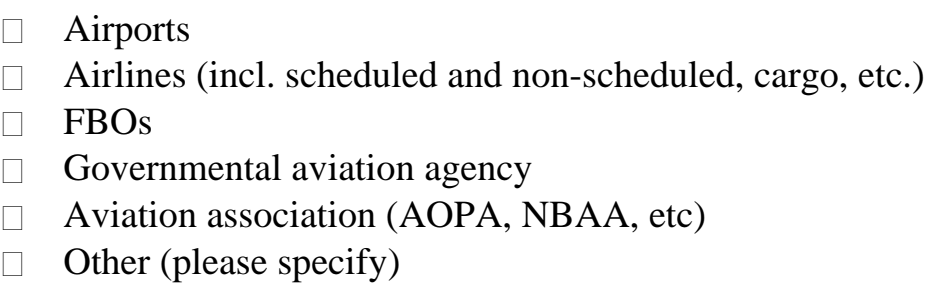

4. Are interns awarded academic credit for successfully completing an aviation internship?

$$
\begin{aligned}
& \text { Yes } \\
& \text { No }
\end{aligned}
$$

5. For a typical internship, how many credit hours are awarded?

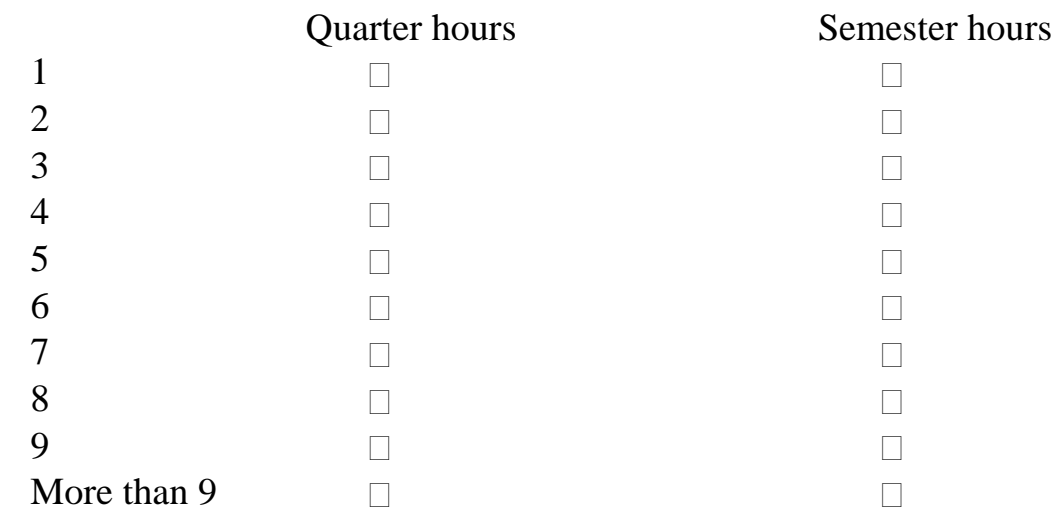


6. In general, how are students graded upon successful completion of an internship?

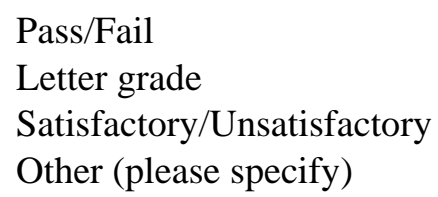

7. Who is responsible for assessing the intern? (Check all that apply)

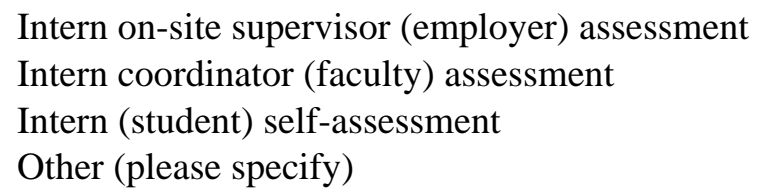

8. Whether your interns are assessed by the employer, internship coordinator, and/or student, which of the following methods are used to assess interns?

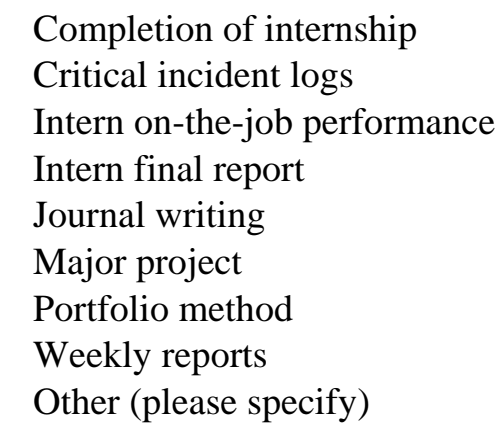

Thank you very much for your time and effort in completing this questionnaire!

Please contact me any comments.

C. Daniel Prather, A.A.E.

Associate Professor of Aerospace

Box 67

Mufreesboro, TN 37128

dprather@mtsu.edu 


\section{Appendix B}

(Adapted from the AAAE Airport Management Internship Program Guide)

Airport Management Internship Program

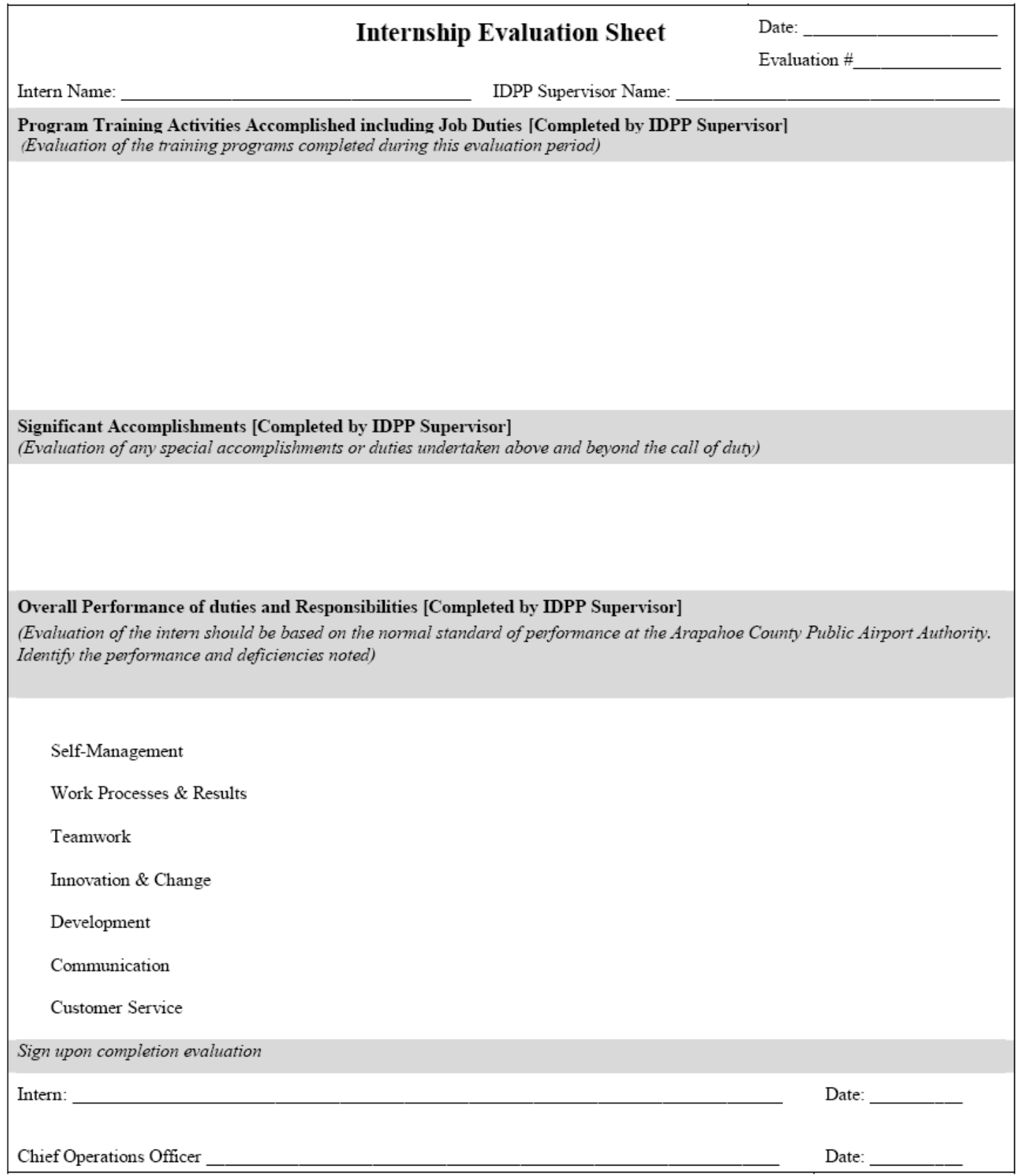




\section{Performance Elements}

\section{Self-Management}

Punctuality \& regular work attendance

Efficient, effective use of work time,

equipment, and resources

Working in a safe manner

Proper use and maintenance of equipment

Seeking and assuming additional

responsibilities as appropriate

Exhibiting integrity and honesty

Treating others with respect and dignity

Giving and accepting constructive feedback

Working effectively in a diverse work environment

Focusing on the situation, issue, or behavior rather than on the person

Other

Work Processes \& Results

Providing products and services that consistently meet or exceed the needs and expectations of customers

Using customer satisfaction as a key measure of quality

Using appropriate problem solving methods to improve processes

Collecting and evaluating relevant

information to make decisions

Using good judgment

Setting and adhering to priorities

Meeting productive standards, deadlines, and work schedules

Accurate and timely work with minimal supervision

Achieving results

Pursuing efficiency and economy in the use of resources

Informing supervisor or others of problems, identifying issues, and alternative solutions

Other

\section{Teamwork}

Supporting and focusing on the vision, mission, and goals of the organization and team

Understanding the benefits of teamwork Cooperating with and offering assistance to others

Recognizing the contributions of others

Viewing the success of the organization and team as more important that individual achievements

Contributing to the development, cohesion and productivity of the team
Appropriately sharing information internally and externally

Supporting teamwork and cooperation through open and honest communication

Other

\section{Innovation \& Change}

Being creative and innovative when contributing to organizational and individual objectives

Receptivity to new ideas and adaptability to new situations

Avoiding being overly defensive; willingness to explore different options

Taking calculated risks

Seeking and acting on opportunities to improve, streamline, re-invent work

processes

Helping others to overcome resistance to change

Other

\section{Development}

Participating in opportunities to enhance knowledge and skills that are identified and offered by the organization or the evaluator Self-initiative in developing or upgrading knowledge and skills

Applying new knowledge or skills squired from developmental opportunities Helping others learn new systems, processes, and programs

Learning to use technology effectively, as appropriate

Other

\section{Communication}

Participating in meetings in an active, cooperative, and courteous manner Orally communicating effectively on a oneto-one basis and in small groups Making effective oral presentations before groups

Writing clearly and succinctly Avoiding "bureaucratese" whenever possible in written and oral communications Demonstrating understanding and empathy with the listener or reader Being responsive and timely to emails, phone messages, and mail Other 


\section{Customer Service}

Understanding and being responsive to customers' objectives and needs

Sensitivity to public attitudes and concerns

Being accessible, timely, and responsive in dealing with customers

Handling customer inquires and complaints promptly and courteously

When possible, going the extra mile to satisfy customer needs and expectations Other 